\title{
T-wave alternans: a harbinger for malignant ventricular arrhythmias
}

\author{
Chandrasekharan Rajasekharan, ${ }^{1}$ Kavadisseril Vivekanandan Vysakha, ${ }^{2}$ \\ Vijayakumar Karthik, ${ }^{1}$ Muralikrishnan Harikrishnan ${ }^{1}$
}

'Department of Internal Medicine, Medical College Hospital, Thiruvananthapuram, Kerala, India

${ }^{2}$ Intenal Medicine, Medical College Hospital, Trivandrum, Kerala, India

\section{Correspondence to} Professor Chandrasekharan Rajasekharan, drcrajasekharan@yahoo.com

Accepted 21 June 2018

\section{DESCRIPTION}

A 50-year-old male chronic alcoholic presented to our emergency department with seizures and loss of consciousness after an alcoholic binge. He had no other significant medical history and was not on any regular medications. On examination, his pulse was 90 beats/min and his blood pressure was $80 / 60 \mathrm{~mm} \mathrm{Hg}$. His resting ECG showed sinus rhythm with QT prolongation. His serum sodium was $133 \mathrm{mmol} / \mathrm{dL}$, potassium was $3.5 \mathrm{mmol} / \mathrm{dL}$, magnesium was $1.4 \mathrm{mmol} / \mathrm{dL}$ and calcium was $6.6 \mathrm{mg} / \mathrm{dL}$. The ECG demonstrated wide QRS tachycardia with a heart rate of approximately 200 beats/min and mild irregularity and morphology suggestive of polymorphic ventricular tachycardia initiated by a ventricular premature contraction falling on the terminal part of the $\mathrm{T}$ wave of the preceding sinus beat (figure 1A, black arrows). The postelectroversion tracing showed sinus rhythm at a rate of 55 beats/min, with alternating small, narrow (figure 1B, red arrows) and broad deep T-wave inversions (figure $1 \mathrm{~B}$, black arrows) with a measured QT interval of $800 \mathrm{~ms}$ and QTc of 769.80 ms suggestive of T-wave alternans (TWA). An emergency two-dimensional echocardiogram showed no regional wall motion abnormality and a normal ejection fraction of $64 \%$. Corrective measures were instituted to restore electrolyte imbalance on an urgent basis, but he subsequently developed an episode of sudden-onset unresponsiveness. Intravenous magnesium sulfate $2 \mathrm{~g}$ bolus dose was administered followed by infusion at $10 \mathrm{mg} / \mathrm{min}$ via central venous catheter and norepinephrine infusion at 15 $\mathrm{mcg} / \mathrm{min}$ was started in view of hypotension. Inj Calcium Gluconate $10 \% 100 \mathrm{~mL}$ was given in
$100 \mathrm{~mL}$ normal saline over $30 \mathrm{~min}$. Attempts at correction of the electrolyte disturbances were unsuccessful, and he developed a ventricular fibrillation and expired despite attempts at resuscitation.

TWA refers to beat-to-beat variability in the timing or shape of $\mathrm{T}$ waves on the surface ECG. It is distinct from electrical alternans totalis, as TWA does not involve the QRS complex. TWA is well known to be a harbinger of malignant ventricular arrhythmias. ${ }^{1}$ The most common form is a microvolt TWA which is undetectable in standard 12-lead ECG and requires advanced signal processing techniques like spectral and modified moving average methods for demonstration. ${ }^{2}$ Rarely as in our case, a macrovolt TWA is demonstrable in the ECG tracing. The presence of TWA might serve as a potential guide for deciding the need for prophylactic implantable cardioverter-defibrillator in patients at risk for sudden cardiac death, namely those with cardiomyopathies, hereditary channelopathies and postmyocardial infarction. This finding is indicative of temporal differences in ventricular repolarisation, an important mechanism underlying re-entrant arrhythmias in TWA. ${ }^{3}$ Patients with acquired long QT syndrome usually develop torsade during periods of bradycardia. The most common causes of acquired long QT syndrome are medications and electrolyte disorders (eg, hypokalaemia, hypomagnesaemia). Several epidemiological studies have identified chronic excessive alcoholism as a risk factor for QT prolongation. ${ }^{4}$ Our patient was a chronic alcoholic and had hypomagnesaemia and hypokalaemia. Hypomagnesaemia in alcoholics is due to inappropriate magnesiuria, possibly due to hypophosphataemia, metabolic acidosis or a direct

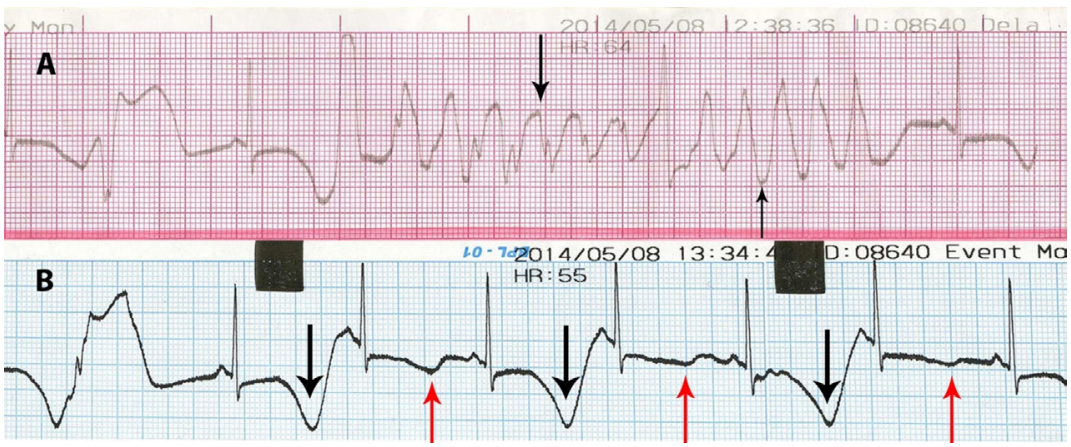

Figure 1 ECG demonstrating wide QRS tachycardia with a heart rate of approximately 200 beats/min and mild irregularity and morphology suggestive of polymorphic ventricular tachycardia initiated by a ventricular premature contraction falling on the terminal part of the T wave of the preceding sinus beat ( $A$, black arrows). The postelectroversion tracing showed sinus rhythm at a rate of 55 beats/min, with alternating small, narrow (B, red arrows) and broad deep T-wave inversions ( $\mathrm{B}$, black arrows). 


\section{Learning points}

- Abnormal depolarisation of the myocyte is the causative mechanism of T-wave alternans (TWA).

- All the conditions producing long QT syndrome, such as medications and electrolyte disorders like hypokalaemia and hypomagnesaemia, pose a risk of sudden cardiac death.

- Vulnerability to ventricular fibrillation, susceptibility to malignant arrhythmias and the risk for sudden cardiac death can be assessed by observing TWA when present.

- It must be borne in mind that TWA has been found to be one of the strongest predictors of sudden cardiac death.

magnesiuric effect of acute alcohol consumption in excess. Alcoholics are prone to hypomagnesaemia, which can predispose them to torsade, as was the case in our patient.

Acknowledgements We acknowledge with sincere gratitude the patient's brother for permitting us to publish the images.
Contributors $C R$ was the primary physician who admitted and treated the patient, conceived the idea of writing the manuscript, and responsible for getting informed consent from the patient's brother. KVV, VK and MH were equally responsible for making the preliminary draft, revising the manuscript, and editing images and collecting references. CR and VK revised again the manuscript.

Funding The authors have not declared a specific grant for this research from any funding agency in the public, commercial or not-for-profit sectors.

Competing interests None declared.

Patient consent Next of kin consent obtained.

Provenance and peer review Not commissioned; externally peer reviewed.

\section{REFERENCES}

1 Holley CL, Cooper JA. Macrovolt T-wave alternans and polymorphic ventricular tachycardia. Circulation 2009;120:445-6.

2 Verrier RL, Klingenheben T, Malik M, et al. Microvolt T-wave alternans physiological basis, methods of measurement, and clinical utility--consensus guideline by international society for holter and noninvasive electrocardiology. J Am Coll Cardiol 2011:58:1309-24.

3 Narayan SM. T-wave alternans and the susceptibility to ventricular arrhythmias. J Am Coll Cardiol 2006:47:269-81.

4 Li Z, Guo X, Liu Y, et al. Relation of heavy alcohol consumption to QTC interval prolongation. Am J Cardiol 2016;118:1201-6.

Copyright 2018 BMJ Publishing Group. All rights reserved. For permission to reuse any of this content visit

http://group.bmj.com/group/rights-licensing/permissions.

BMJ Case Report Fellows may re-use this article for personal use and teaching without any further permission.

Become a Fellow of BMJ Case Reports today and you can:

- Submit as many cases as you like

- Enjoy fast sympathetic peer review and rapid publication of accepted articles

- Access all the published articles

- Re-use any of the published material for personal use and teaching without further permission

For information on Institutional Fellowships contact consortiasales@bmjgroup.com

Visit casereports.bmj.com for more articles like this and to become a Fellow 